\section{H. STRICTICOLLIS.}

Head narrow, elongate; body rather slender; one postocular; ventral shields distinct, only the anterior being twice as broad as the adjoining series, 398 in number.

\section{H. Ornata.}

Head rather narrow, and produced; body somewhat elongate; two post-oculars; ventral shields twice as broad as the adjoining scales, 252 to 260 in number. Scales with a central tubercle, the first upper temporal shield much larger than high.

\section{H. Elimotit.}

Head rather thick and short; body of moderate length; two post-oculars; ventral shields nearly twice as broad as the adjoining scales, 253 to 258 in number. The first upper temporal shield is not much larger than high; thirty-five or thirty-seren series of scales round the neck.

\section{H. Pachycercus.}

Head and body of moderate width and length; two postoculars; nasal shields longer than broad, ventrals more than twice as broad as the scales, 258 in number. The first upper temporal shield longer than high; twenty-eight series of scales round the neck.

\section{H. VIPERINA.}

Head of moderate size and width; body of moderate length two post-oculars; nasal shields as broad posteriorly as they are long; anterior ventral shields broad.

\section{H. HARDWICKII.}

Head short and thick; body stont; one post-ocular; no distinct ventral shields. Trunk with from forty-one to fortythree blackish cross bands, not extending downwards to the belly.

\section{SUMMARY OF EXPERIMENTS ON THE INFLUENCE OF SNAKE POISON.}

By J. FAYrer, M.D., C.S.I.

THE experiments, of which this is a summary, were commenced in October, 1867, and have been continued as regularly since, at such intervals, as time and other and more important avoeations permitted. My object has been to determine by actua observation, the effect on life of the poison of the venomou snakes of this country, and to test the value venomous whether internal or external.

So many absurd ideas on the subject prevail, that it is desirable to know the real truth, not less with reference to the ac tual modus operandi of the poison, than to the value of the many vaunted antidotes. The results, I regret to say, tend to shew that, in the present state of our knowledge, we can do little to counteract or neutralize the action of the poison; but what may be expected from treatment I have endeavoured to shew.

As to antidotes, I would speak with reserve on the subject of possible future discoveries; my experience does not encourage me to hope that we shall discover anything that can be regarded as an antidote, such as is generaily meant by that term. But considering the imperfection of our knowledge on this and kindred subjects, I would do naught to deter or discourage others from further investigation.

My personal experience is derived from the action of the poison in the lower animals, and a few cases in man; the antagonism of the venom to the vital forces is shewn in one as well as in the other, and is no doubt subject to the same laws. The deductions from one are applicable to the other.

The greatest care has been observed in all the experiments, and most of them have been often repeated, to exclude as far as possible, sources of error, and to obviate generalization from insufficient data.
Almost every experiment has been witnessed by competent observers, to whom I am much indebted for their assistance, and for the additional value which their presence attaches to the validity of what was done.

The object of investigation has been the simple truth. I can safely say there was neither foregone conclusion to maintain nor theory either to support or oppose.

The snakes with which the experiments have been conducted were :-

The varieties of Naja Tripudians or Cobra.

The Ophiophagus Elaps or Hamadryad.

The Bungarus Fasciatus or Sankni.

The Bungarus Cœruleus or Krait.

Some of the Hydrophidæ.

The Daboia Russelli.

The Echis Carinata.

The Trimeresurus Monticola.

And in the ease of the Calophides and the other Crotalidæ, I have referred to the experiments of others, not having had opportunity of testing them myself.

The living creatures experimented on have been the $o x$, horse, goat, pig, dog, cat, civet, mongoose, rabbit, rat, fowls, kites, herons, fish, innocent snakes, poisonous suakes, lizards; frogs, toads, snails.

The symptoms produced by the poison both constitutionally and locally hare been carefully noted. The state of the blood has also been examined, especially with reference to structural changes,-and for this part of the investigation, I have been much indebted to Professors Partridge, Ewart, W. Palmer, J. Anderson, and Dr. Douglas Cunningham.

In point of relative deadliness, I should be inclined to consider that the cobra, opbiophagus, and daboia are very nearly on a par. They are quite capable of destroying a fullgrown $\operatorname{dog}$ in half an hour, sometimes in much less time; and very frequently I believe man has succumbed within an equally short period, though generally the time is much longer.

The bungarus cœruleus is, I believe, just as deadly, but apparently does not kill quite so quickly. The bungarus fasciatus is less fatal, and kills less quickly than the bungarus cœruleus. The echis, if one may credit the reports from Scinde, and they are confirmed, to a certain extent, by Major MacMahon, Deputy Commissioner of Delhi,-is also a very deadly suake. It destroys life rapidly in small animals, but from its small size, it is perhaps less likely to be fatal to man, though from what $I$ have seen of the effects of its poison on pigeons, fowls, and dogs, I should regard it with peculiar

Of the Hydrophidæ less is known, but the few experiments I have performed, and those by Mr. Stewart, prove that they are very fatal, and I should think human life would be in great danger from their bite.

The Calophides and Crotalidæ of Hindustan are certainly not so deadly as those I have mentioned, and though capable of inflicting a painful, and in some instances, no doubt, a dangerous bite, they are not so much dreaded as the other
snakes.

There are differences in the symptoms produced by the poisonous bites of the different Thanatophidia, but none of any great physiological or pathological import. In some cases convulsions are more marked, and in others death is preceded by a more marked appearance of lethargy. In some, as in those of the echis, the local symptoms are peculiarly severe, in others less so. But the differences are more of degree than of kind. They all point to exhaustion and paralysis of the nerve centres-the sources of the origin of vital force-every function fails rapidly
and vitality is soon extinct.

Local paralysis of the bitten part, great depression, faintness 
exhaustion, nausea, vomiting, hæmorrhage, relaxation of the splincters, involuntary evacuation, not unfrequently of a sanguineous or muco-sanguineous character, precede the complete loss of consciousness, and after this convulsions occur just before life ceases.

The post-mortem appearances frequently reveal simply nothing except the marks of the fangs and the slight ecchymosis about them; or if the creature have survived some hours, infiltration and, perhaps, incipient decomposition of the tissues, The lungs are not generally congested, the heart is not generally overloaded, the viscera look natural enough, death is not traceable to special disturbance of any one great function such as respiration, and the blood, after death, in the cases of the lower animals, certainly, (and if in them, why not in man)* nearly always coagulates firmly on removal from the body, after death, from poisoning by the colubrine snakes. But in death by viper poisoning it remains permanently fluid. The cause of this I am quite unable to explain, but there can be no doubt of the facts as regards the lower animals, for they have been proved by often repeated experiments.

From experiment I have arrived at the following conclusions. - Snake poison acts with most vigor on the warmblooded animals; birds succumb very rapidly, a vigorous snake can destroy a fowl in a few seconds.

The power of resistance is generally in relation to the size of the animal, though not altogether so; cats, for example, resist the influence of the poison almose as long as dogs three or four times their size.

The cold-blooded animals also succumb to the poison, but less rapidly. Fish, non-venomous snakes, mollusca, all die. So far as I can decide from experience the poisonous snakes are not affected by their own poison, i.e., a cobra may bite itself, or another cobra, and with no evil result.

The less are probably affected by the more poisonous snakes, e. $g$., the bungarus seem to be affected by cobra poison, though slowly.

It is possible that they can all to some extent affect each other, though infinitely less than other animals. In many of the various experiments I have performed, the cobra, daboia, and krait did not appear to be able to poison themselves or each other. Some of the experiments render this doubtful; and seem to shew that a cobra or daboia may poison a krait, or vice vers $\hat{a}$, but that they escape more frequently than they suffer.

Snake poison is absorbed through delicate membranes. It is deadly when applied to a mucous or serous membrane, to the stomach, or the conjunctiva. The idea that it is only capable of absorption by direct injection into the blood is erroneous.

The blood of animals poisoned to death by the colubrine snakes coagulates after death. That of animals poisoned by the viperidæ remains permaneritly fluid.

The bodies of animals poisoned by snakes are eaten with impunity by man and animals. I have had repeated proofs of this. The fowls and pigeons killed in my experiments were always taken away and enten by the sweepers who were present, and who sought them greedily. They were not unfrequently given to dogs or cats, no harm followed.

The blood of an animal dead from snake poisoning is itself poisonous; if injected into another animal it destroys life. This shews the intensity of the poison: a drop or two diluted with the blood of a fowl or animal renders the whole poisonous. Venomous snakes, though not at all, or very slightly, affected by snake poison, are very susceptible to other poisons, such as

* It is to be noted that in most recorded post-mortem examinations of human beings, who have died from snake bite (whether colubrine or viperine) the blood is noted to have remained fluid after death. I cannot reconcile this with the condition of the blood in animals which is, as I have stated, coagulable after death, from colubrine poisoning, fluid after death, from viperine poisoning. Further examination is needed. strychnine or carbolic acid. The latter destroys them very rapidly, and they seem to regard it with peculiar aversion. Poisonous snakes are not as a general rule very aggressive, except perhaps the echis. They seek to be left in quiet, to be let alone. They bite only if disturbed or irritated, and even then they often will not bite, but make one or two strikes at the enemy as if to frighten it.

In my experiments, I had always the greatest difficulty to get the cobra, krait, or daboia to bite voluntarily. An animal may remain in a cage or box with a cobra or daboia a very long time before it is injured, and perhaps, after all, it is taken out untouched, even after trampling on and bruising the snake, in its efforts to escape from its enemy, which is as much frightened as itself. There is much hissing and demonstration of attack, but frequently nothing done. If pressed and overteazed, they bite at last, and if they insert their fangs and retain their hold, the bite is generally fatal.

The echis, however, will strike and mortally wound a fowl or small animal directly it approaches it, and its dart is so rapid that it is scarcely seen.

Snakes frequently strike and even wound without poisoning, or very slightly so. The fang merely scratches and makes a tear, but if inserted and retained for a second the poisonous bite has then been inflicted. Of course, any abrasion or scratch, however trivial, may be dangerous, as some of the virus may be inoculated or shed over it, probably not enough to kill, but sufficient to cause dangerous symptoms.

A snake that has bitten often, or that has very recently eaten, or that has been long in confinement without food, is less dangerous than others; its bite may be almost harmless, though not always so:- a daboia that lived a whole year in a cage without food, was deadly a few days before its death.

The popular notions as to the effects of the so-called antidotes are, I believe, erroneous; such for the most part being utterly powerless or inert. The ligature, excision or cautery if applied in time, are the only rational remedies that can be of arail in a really poisonous bite. Others are recovered from by the inherent vigor of the person bitten, aided by rational treatment, support, stimulants, and possibly to some extent by arsenic, iodine, bromine, or potass or others of the many remedies recommended, but as antidotes in the ordinary acceptation of the term, even these, I fear, are no better than others.

The poisonous snakes when they either shed or lose by accident their fangs, regain new ones, in from a few days to a month or six weeks. An echis was re-furnished with fangs, firmly anchylosed to the maxillary bone, on the third day after the removal of the former ones. If the whole mucous capsule be removed, and the maxillary bone injured in extracting the fangs, the reserve teeth already developed and the germs are also destroyed, and no new fangs are reproduced. This is often done by the snake-catchers, but when imperfectly, and the reserve fangs and germs not destroyed, fatal accidents have occurred from the unexpected reappearance of fangs.

Snakes cast their epidermis frequently; the cobra and krait once or twice in a month, but the echis I have kept for three months without its changing its skin. Snakes will live months without food or water. A daboia lived for one year without food. It moulted frequently, became very thin, but it was active and poisonous to the last.

I conclude the summary by remarking that i feel thankful that I have brought this long series of experiments to a conclusion without any accident of a serious nature to those concerned in them. The constant manipulation of excited and vicious venomous snakes, is a service of danger, and one in which we could hardly expect to be long engaged without some casualty. I am happy to say that only on two occasions was there any cause for anxiety. In the first, one of my assistants 
had a small quantity of cobra poison projected into the eye. Immediate ablution and careful aroidance of rubbing re. moved it, leaving only a temporary congestion and weakness of eye.

In the second case my principal snake-man was bitten by an echis in the thumb; immediate excision and cauterization of the part was had recourse to, and no evil results followed.

\section{ON THE IMMEDIATE TREATMENT OF PERSONS BITTEN BY VENOMOUS SNAKES.}

By J. FAYRER, M.D., C.S.I.

IT is, I believe, usual to supply the police thannahs with liq. ammoniæ, to administer to those who are bitten, and who come under the notice of the police, before they can be brought under any medical treatment.

The practice is a good one, and I would adrocate its conti. nuance and extension. Ammonia is a powerful stimulant and may do good-it cannot do any harm; administered in doses of ten or fifteen drops with half a wine glass (chittack) of water, every quarter of an hour, or even more frequently, it may be of benefit; and, as in the police stations and elsewhere in England, tables giving general instructions for the treatment of the drowned or suffocated, are hung up by the Humane Society, so in the Indian police stations, and other public places where such might be useful, I would hang up tables giving brief and clear instructions how to act in the case of snake-bite.

As soon as possible after a person is bitten by a snake, apply a ligature, made of a piece of cord, round the limb or part at about two or three inches above the bite.

Introduce a piece of stick or other lever between the cord and the', part, and by twisting, tighten the ligature to the utmost.

Apply other two or three ligatures above the first one at intervals of 4 or 6 inches, and tighten them also. After the ligature has been applied scarify, by cutting across the punc. tures to the depth of $\frac{1}{4}$ of an inch with a pen-knife or other similar cutting instrument; let the wounds bleed freely; or better still excise the punctured part.

Apply either a hot iron or a live coal to the bottom of these wounds as quickly as possible, or some carbolic or nitric acid.

If the bite be not on a finger, toe, or part where a ligature can be applied, raise up the integument with the finger and thumb, and with a sharp penknife cut out a circular piece as big as a finger nail, round each puncture, $i$. $e$, round the points of the finger and thumb, to the depth of $\frac{1}{4}$ or $\frac{1}{2}$ an inch. Then apply the hot coal or hot iron to the very bottom of the wounds.

Give fifteen drops of liq. ammoniæ, diluted with an ounce of water, immediately, and repeat it every quarter of an hour, for 3 or 4 doses, or longer, if symptoms of poisoning appear.

Or give hot brandy or rum or whisky or spirits, with equal parts of water, about an ounce of each (for an adult) at the same intervals. Send at once for medical aid; or take the person to the nearest medical man without delay; if none be near-in half an hour, should no symptoms of poisoning have appeared, the ligatures should be relaxed, or the part will perish from gangrene.

If symptoms of poisoning do appear, do not relax the ligatures until the person be recovering from the poison, or until the ligatured part be cold and livid.

Suction of the wounds is likely to be beneficial, but as it may be dangerous to the operator, it cannot be recommended as a
duty.

If, notwithstanding, symptoms of poisoning set in and increase, if the patient become faint or depressed, unconscious, nauseated or sick,-apply mustard poultices, or liq. ammoniæ on a cloth, over the stomach and heart; continue the stimulants and keep the patient warm, but do not shut him up in a bot stifling room, or a small native hut,-rather leave him in the fresh air than do this.

Do not make him walk about if weary and depressed; rouse with stimulants, mustard poultices or ammonia, but let him rest.

If the person be brought, as he or she probably will be, some time after the bite has been inflicted, and symptoms of poisoning are present, the same measures are to be resorted to. They are less likely to be successful, but nothing else can be done.

In many cases, the prostration is due to fear, the bite may have been that of a harmless or exhausted snake, and such will rapidly recover if so treated and encouraged. If poisoned, but, as frequently is the case, not fatally, these measures are the most expedient; if fatally poisoned, no others are likely to be more efficacious.

It will frequently happen that the bitten person is seen by an educated person (though not a medical man) who may have the opportunity of applying the magnetic or electric current to the heart and diaphragm, or of making other additions to the measures already described. By such, the so-called antidotes may be given, though I fear they can add but little if any benefit. The snake should always, if possible, be produced.

The measures suggested are no doubt severe, and not such as under any other circumstances should be entrusted to nonprofessional persons.

But the alternative is so dreadful, that even at the risk of unskilful treatment, it is better that the patient should have this chance of recovery.

In addition to a supply of liq. ammoniæ to all police thannahs or other public localities away from the dispensaries and stations where the ryots might apply for aid in case of bites, I would suggest the addition of a small supply of strong whip cord, an actual cautery iron and a small knife for the purposes I have described, and a bottle of carbolic or nitric acid.

A plain summary or translation of these suggestions might be hung up in every police thannah and other public place. The people should be warned against incantations, popu lar antidotes, and loss of time in seeking for aid.

Every Police Inspector, of whatever grade, might be taught the application of the simple measures I have described, and should be enjoined to make them known as widely as possible among the police and the people.

\section{ON FISH AS FOOD OR THE REPUTED ORIGIN OF DISEASE.}

\section{By Surgeon Francis $\mathrm{D}_{\Delta \mathrm{X}}$, F.L.S. \& F.Z.S., Mradras Army. (Continued from page 8.)}

IT is impossible to detail here all the most wholesome genera and species of Indian fishes; still a few remarks may be made upon their general digestibility, premising that certain local peculiarities may exist in places, altering the otherwise usual excellent character of a fish.

Amongst the Acanthopterygians, or spiny rajed fishes, all that are found in the Indian fresh waters appear to be adapted as food, without setting up deleterious effects. Religious prejudices may militate against the employment of some species, but not sanitary reasons; unless the last may have been due to any substances swallowed by the fish. Thus at one time the Gouramy, Osphromenus gouramy, Lacèp., in a tank in dis Marit for human food, when it was discovered that they consumed the filth from beneath a latrine which opened into it. Hanilton Buchanan observed of the Scatophagus argus, Bl., (Chatodon pairatalis, H. B.,) that it is 